\title{
A Representative Driving Cycle for the Southern Expressway Compared to Existing Driving Cycles
}

\author{
Uditha Galgamuwa $^{1} \cdot$ Loshaka Perera $^{1} \cdot$ Saman Bandara $^{1}$
}

Received: 3 November 2015/Accepted: 13 August 2016/Published online: 16 September 2016

(C) Springer International Publishing Switzerland 2016

\begin{abstract}
This paper critically evaluates traffic related performance of the Southern Expressway (SEW) in Sri Lanka using basic traffic engineering parameters such as average speeds, acceleration-deceleration changes, root mean square acceleration, and positive kinetic energy. An on-road speed/time data sample was collected, and a driving cycle was developed to compare to well-established driving cycles worldwide. Ten traffic-related parameters were identified in order to evaluate the SEW using the collected data. Data was collected in proportion to the number of actual trips made by users on an average day using the on-board method; the segment-based method was adopted for cycle construction. Previously identified traffic-related parameters were used to evaluate and select representative cycle for the SEW from candidate cycles. The selected driving cycle was $1213 \mathrm{~s}$ in length. Average speed, average acceleration, and average deceleration were $80.6 \mathrm{~km} / \mathrm{h}, \quad 0.45$, and $0.25 \mathrm{~m} / \mathrm{s}^{2}$, respectively. Results showed that both average and running speeds of the SEW were significantly below compared to its posted speed limit, thereby increasing the travel time. Comparatively smooth driving behavior will improve the SEW's fuel and emission performances. This study created a platform with which future studies can evaluate performances of all operational and future expressways.
\end{abstract}

Keywords Performance evaluation - Expressway driving cycles · Driving cycle comparison - Route selection - Cycle construction $\cdot$ Cycle assessment

Uditha Galgamuwa

nandun8781@gmail.com

1 Transportation Engineering Division, Department of Civil Engineering, University of Moratuwa, Colombo, Sri Lanka

\section{Introduction}

Transport emissions are the major contributory source of air pollution; thus emission standards play a major role in controlling vehicular emissions. Many countries use driving cycles to determine regional vehicular emissions due to traffic patterns. Using measured emission inventories as baseline emission, standards are set up or emission zones are established to control emissions. A driving cycle is a series of data points that represents speed versus time [1], speed and gear selection as a function of time [2], speed versus distance [3], or time versus gradient [4] in a specific region or part of a road segment. Driving cycles have been used throughout the world for traffic engineering [5] and emission purposes $[2,6,7]$ and to estimate fuel consumption [8]. In order to estimate fuel consumption and develop emission inventories by collecting total emission, a test vehicle is run on a chassis dynamometer according to developed driving cycles. The collected emissions are analyzed using a gas analyzer [9-11].

Sri Lanka developed a driving cycle in 2012 for the capital city of Colombo [12] in order to obtain an approximate estimate of emission inventories and clarify existing emission standards with an enhanced driving cycle. However, another driving cycle was recently developed for Colombo that more accurately represents local traffic behavior. This new development eliminated some major drawbacks of the previous driving cycle.

The first expressway constructed in Sri Lanka was the Southern Expressway (SEW), which is $108 \mathrm{~km}$ long with two lanes ( $3.5 \mathrm{~m}$ per lane) in either direction, a center median of $1.5 \mathrm{~m}$, hard shoulders of $1.75 \mathrm{~m}$, a posted speed limit of $100 \mathrm{~km} / \mathrm{h}$ (no minimum speed), and ramps at entry and exit points [13]. This toll road was open to the public in September 2012 to provide an alternative to Galle Road 
(A002) to connect capital (Colombo) and the southern part of the island. Excessive access roads and connections to main cities make Galle Road extremely congested, requiring more than $3 \mathrm{~h}$ for a trip of $115 \mathrm{~km}$ from Colombo to Galle during peak hours. The SEW, which starts in Kottawa and ends in Galle, has eight entry/exit points located at approximate equal distances, and average daily traffic (ADT) is about eleven thousand $(11,000)$ vehicles. In 2014, however, after this study was conducted, an extension from Galle to Matara $(32.6 \mathrm{~km})$ was made to the SEW, allowing increased traffic volume. Large vehicles, including buses, are allowed on the SEW, but motorcycles or three-wheelers are prohibited. Although this expressway has been in operation for several years, prior to the current investigation, no study had yet been carried out to evaluate traffic-related performance or emission on the SEW.

Driving cycles have been developed worldwide, including driving cycles for freeways and high mobility roadways, such as EMPA C-3/C-6 and Artemis HighMotmotorway-total developed in Switzerland and Europe, respectively. The primary objective of this study was to develop a driving cycle for the SEW to determine trafficrelated parameters and compare those parameters to previous driving cycles. Developing a driving cycle is difficult, however, because spatial and temporal characteristics of traffic flow differ between countries or regions. Therefore, four major steps were identified to capture characteristics necessary to develop a representative driving cycle: route selection, data collection, cycle construction [14], and cycle assessment [12]. An in-depth literature review was also carried out to determine appropriate methodology for developing a driving cycle for expressways in Sri Lanka.

\section{Literature Review}

Route selection is a primary aspect of driving cycle development since selected routes should represent traffic behavior in the targeted area in order to avoid biased collected data and driving cycle results that deviate from its actual condition. Selected routes should accurately represent traffic flow and other conditions related to traffic (spatial and temporal), land use, road type, topography, and population density [1, 15]. Hong Kong, China and Hanoi, Vietnam driving cycles use experience and knowledge of local traffic conditions and defined origin/destination pairs with average annual daily traffic (AADT) and then the frequently used routes are selected for data collection by considering the time of day $[14,16]$. Route selection in the Bangkok, Thailand driving cycle was based on traffic flow data and travel speed. Using traffic flow data, a traffic flow model was developed to determine the travel speed along each section of major roads. A distribution map of vehicle travel speeds in the area was then established [17]. Routes in Sydney, Australia were selected according to road classification and traffic density in areas with highest emissions; time period of data collection was selected by conducting an Origin-Destination (O-D) survey [18].

Data collection is vital for driving cycle development. Data collection methods can generally be categorized as the chase car method or the on-board measurement method [19]. Data can also be collected using the hybrid method, which is a combination of the chase car and on-board measurement methods [1]. Because driving patterns can vary according to engine capacity, engine capacity of the vehicle should be considered [20]. In the on-board measurement method instruments are installed on selected vehicles, vehicles are allowed to freely travel along the traffic stream, and speed data is recorded every second as the vehicles travel along predetermined routes. This method advantageously obtains the direct measurement of speed data since the chase and chased vehicle are identical, thereby overcoming delay due to driver response time [1]. However, when using on-board measurement method the route is predetermined, so the driving pattern could differ from the actual driving pattern [1] since the driver is aware of being monitored. This method also requires that equipment be mounted directly to the vehicle, leading to increased costs.

Method of cycle construction varies with the driving cycle such as estimation of emission inventories, estimation of fuel consumption, or traffic engineering purposes. Each cycle construction method uniquely represents its envisioned purpose. There are four methods namely microtrip-based, segment-based, pattern classification, and modal cycle construction. Each method has inherent advantages and limitations [21]. For example, microtripbased cycle construction cannot be used if no or less stops exist between the origin and the destination. In addition, modal cycle construction requires various speed ranges and acceleration rates.

Cycle assessment, the final step of driving cycle development, ensures that the developed cycle represents actual driving in a region. Many countries use various methods and statistical parameters to assess their developed cycles. Commonly used statistical categories are maximums/minimums, percentages, means, and standard deviation of identified parameters. Researchers have also used emission and fuel specific parameters to evaluate developed cycles, such as average road power, root mean square (RMS) acceleration, and positive kinetic energy (PKE) [21]. Considering the various methods used by different countries, the following methodology was adopted to construct a driving cycle for the SEW from Kottawa to Pinnaduwa. 


\section{Methodology}

\section{Route Selection}

Route selection did not require consideration of alternative factors since the study objective was to determine basic traffic-related parameters for the SEW. Population density and land use pattern also were not considered because they did not affect traffic behavior on the expressway road due to limited access (eight entries for $108 \mathrm{~km}$ ). Nevertheless, origin and destination were shown to be highly influential on driving behavior, so OD data was considered. O-D data was extracted from ticketing data available at Road Development Authority in Sri Lanka.

Using average values for each segment, an average O-D matrix for trips made in 1 day was developed, as shown in unshaded rows in Table 1. Fifty-six O-D pairs were identified from the matrix in Table 1 . When the matrix values were rearranged in ascending order, $62.5 \%$ of the values (vehicle travel between $\mathrm{O}-\mathrm{D}$ ) represented less than $15 \%$ of total vehicle travel on the SEW. Therefore, routes representing such O-D trips had less impact on the representative driving cycle; $\mathrm{O}-\mathrm{D}$ entries were removed up to 15 th percentile value, and remaining values in the cells were divided by the value of the 15 th percentile in order to identify minimum required sample size, as shown in bolded numbers in Table 1 . The remaining $37.5 \%$ of O-D pairs, which truly represented $85 \%$ of the total number of vehicles travelling on the road, was used for data

Table 1 OD matrix for trips made in SEW on a typical day (source: Road Development Authority, Sri Lanka)

\begin{tabular}{lrrrrrrrr}
\hline & KOT & KT & GG & DG & WP & KGH & BG & PD \\
\hline KOT & 0 & 150 & 1002 & 465 & 246 & 376 & 121 & 1248 \\
& $\mathbf{0}$ & $\mathbf{1}$ & $\mathbf{1 0}$ & $\mathbf{4}$ & $\mathbf{2}$ & $\mathbf{4}$ & $\mathbf{1}$ & $\mathbf{1 2}$ \\
KT & 147 & 0 & 99 & 65 & 27 & 43 & 11 & 104 \\
& $\mathbf{1}$ & $\mathbf{0}$ & $\mathbf{0}$ & $\mathbf{0}$ & $\mathbf{0}$ & $\mathbf{0}$ & $\mathbf{0}$ & $\mathbf{1}$ \\
GG & 1073 & 91 & 0 & 144 & 61 & 76 & 20 & 201 \\
& $\mathbf{1 0}$ & $\mathbf{0}$ & $\mathbf{0}$ & $\mathbf{1}$ & $\mathbf{0}$ & $\mathbf{0}$ & $\mathbf{0}$ & $\mathbf{2}$ \\
DG & 481 & 53 & 129 & 0 & 37 & 44 & 9 & 86 \\
& $\mathbf{5}$ & $\mathbf{0}$ & $\mathbf{1}$ & $\mathbf{0}$ & $\mathbf{0}$ & $\mathbf{0}$ & $\mathbf{0}$ & $\mathbf{0}$ \\
WP & 197 & 19 & 50 & 43 & 0 & 39 & 9 & 49 \\
& $\mathbf{2}$ & $\mathbf{0}$ & $\mathbf{0}$ & $\mathbf{0}$ & $\mathbf{0}$ & $\mathbf{0}$ & $\mathbf{0}$ & $\mathbf{0}$ \\
KGH & 364 & 35 & 63 & 39 & 42 & 0 & 44 & 183 \\
& $\mathbf{4}$ & $\mathbf{0}$ & $\mathbf{0}$ & $\mathbf{0}$ & $\mathbf{0}$ & $\mathbf{0}$ & $\mathbf{0}$ & $\mathbf{2}$ \\
BG & 112 & 10 & 27 & 6 & 12 & 38 & 0 & 45 \\
& $\mathbf{1}$ & $\mathbf{0}$ & $\mathbf{0}$ & $\mathbf{0}$ & $\mathbf{0}$ & $\mathbf{0}$ & $\mathbf{0}$ & $\mathbf{0}$ \\
PD & 1907 & 94 & 172 & 95 & 51 & 191 & 67 & 0 \\
& $\mathbf{1 8}$ & $\mathbf{0}$ & $\mathbf{2}$ & $\mathbf{0}$ & $\mathbf{0}$ & $\mathbf{2}$ & $\mathbf{0}$ & $\mathbf{0}$ \\
& & &
\end{tabular}

KOT Kottawa, KT Kahathuduwa, $G G$ Galanigama, $D D$ Dodanduwa, $W P$ Walipanna, $K G H$ Kurudugahahathamma, $B D$ Baddegama, $P D$ Pinnaduwa collection. Collected data for selected O-D pairs are shown in Table 2.

\section{Data Collection}

This research adopted an on-board measurement method with modifications in order to eliminate inherent disadvantages. A driving cycle for light vehicles only was initially developed since a majority of vehicles on the SEW are light vehicles. Therefore, light vehicles were selected for data collection using five handheld GPS devices (Qstarz BT-Q1300ST Sports Recorder). GPS devices were given to SEW users at the entrance and collected at the exit. The number of users from each entry point was selected based on their destination on the expressway (approximately proportionate to the O-D population matrix for trips made on an average day, as depicted in Table 1). The cost of data collection was reduced significantly since existing users were used for data collection instead of an intentional fleet of vehicles, thereby allowing collection of extensive trip data, totaling 86 trips on the day of the survey, approximately equivalent to $56 \mathrm{~h}$, from 5:00 a.m. to 9:00 p.m. on both directions on the SEW. The trip summary is presented in Table 2. The literature suggested that a weightage should be given to traffic volumes to capture effects from other vehicular volumes on the expressway with time [1]. Since the SEW currently operates well below its capacity, no peak or off-peak was observed. Therefore, sample trips were not weighted according to the time period of the day; they were considered at equal levels.

\section{Cycle Construction}

After considering prevalent limitations in the other cycle construction methods, segment-based cycle construction was selected as most suitable for developing a driving cycle for the SEW [21]. This method utilizes a trip segment, obtained by partitioning vehicle speed-time profiles

Table 2 Actual trips made for data collection

\begin{tabular}{lrrrrrrrr}
\hline & KOT & KT & GG & DG & WP & KGH & BG & PD \\
\hline KOT & 0 & 1 & 10 & 4 & 2 & 4 & 1 & 12 \\
KT & 1 & 0 & 0 & 0 & 0 & 0 & 0 & 1 \\
GG & 10 & 0 & 0 & 1 & 0 & 0 & 0 & 2 \\
DG & 5 & 0 & 1 & 0 & 0 & 0 & 0 & 0 \\
WP & 2 & 0 & 0 & 0 & 0 & 0 & 0 & 0 \\
KGH & 4 & 0 & 0 & 0 & 0 & 0 & 0 & 2 \\
BG & 1 & 0 & 0 & 0 & 0 & 0 & 0 & 0 \\
PD & 18 & 0 & 2 & 0 & 0 & 2 & 0 & 0 \\
\hline
\end{tabular}

KOT Kottawa, KT Kahathuduwa, $G G$ Galanigama, $D D$ Dodanduwa, $W P$ Walipanna, $K G H$ Kurudugahahathamma, $B D$ Baddegama, $P D$ Pinnaduwa 
using changes in roadway type or levels of service other than stops, to construct the driving cycle [22]. However, the objective of this study was to develop traffic related parameters for the SEW, no information on Level of Service (LOS) was currently available and segmentation according to road type was impossible. Road characteristics also were identical throughout the expressway, so segmentation of on-road data cannot be done using geographical points on the road. The Bangkok driving cycle uses travel speed to partition road segments [17], and many traffic-related analysis road segments with similar geometric features, especially degree of curvature, have been identified using speed ranges [23]. Similarly, travel speed was used to partition the data set for the SEW. However, many outliers were present in the collected data set. Consideration of mean as the representative speed value was not accurate. An example would be the Australian Composite Urban Driving Cycle [24] in which medians were used to as evaluation parameters.

First, the SEW was divided into $1 \mathrm{~km}$ segments, and average travel times, which acted as point estimators, of each trip in each segment were calculated. Median travel time of those segments were then used as a representative value. Previous research has determined that spot speed of a vehicle has an approximately normal distribution $[25,26]$, but heavy tails are possible if traffic volume exceeds road capacity or if traffic moves freely [25]. Research has also shown that the space mean speeds of vehicles are normally distributed [27]. Because the number of data samples was limited in this research, space mean speed was assumed to have a t-distribution, and the median values were then investigated to determine if they accurately represented the selected segments. Significant variation of speeds was found in some segments with the median value. According to the results, segments were further narrowed down to 23 links by combining the adjacent segments with approximately equal median travel times were combined. Some links were not combined due to considerably different speed variations although travel time medians were identical. The selected 23 links are shown in Table 3. However, working with such a large data set is very difficult, and manual selection of data for a driving cycle is almost impossible. Therefore, software was developed (DC2013) using JAVA programming language to utilize the large data set and develop a number of candidate driving cycles using the segment-based cycle construction method.

A KML point file was initially prepared that consisted of latitudes and longitudes of start and end points of each segment. The file was then input into the software for data set segmentation according to identified road segments. Each trip snippet was assigned to cluster bins using mean speed of each snippet, and the snippets
Table 3 Detail of the selected points for segmentation

\begin{tabular}{lll}
\hline & Point name & Distance to next point $(\mathrm{km})$ \\
\hline 1 & Kottawa & 1 \\
2 & Kahathuduwa1 & 3 \\
3 & Kahathuduwa2 & 3 \\
4 & Kahathuduwa0 & 4 \\
5 & Galanigama1 & 4 \\
6 & Galanigama2 & 4 \\
7 & Galanigama0 & 5 \\
8 & Dodangoda1 & 6 \\
9 & Dodangoda2 & 7 \\
10 & Dodangoda3 & 6 \\
11 & Dodangoda0 & 4 \\
12 & Welipanna1 & 5 \\
13 & Welipanna2 & 4 \\
14 & Welipenna0 & 6 \\
15 & Kurdugahahathamma1 & 8 \\
16 & Kurudugahahathamma2 & 8 \\
17 & Kurudugahahathamma0 & 5 \\
18 & Baddegama1 & 3 \\
19 & Baddegama2 & 3 \\
20 & Baddegama3 & 3 \\
21 & Baddegama0 & 4 \\
22 & Pinnaduwa1 & 6 \\
23 & Pinnaduwa2 & 6 \\
\hline & &
\end{tabular}

were chained by the software to develop candidate cycles.

\section{Cycle Assessment}

In order to evaluate a driving cycle for light vehicles on the SEW (DC-SE-SL-LV), the following ten commonly used statistical parameters were selected as discussed in the literature review:

1. Average speed $(\mathrm{km} / \mathrm{h})$

2. Average running speed $(\mathrm{km} / \mathrm{h})$

3. Average acceleration $(\mathrm{km} / \mathrm{h} / \mathrm{s})$

4. Average deceleration $(\mathrm{km} / \mathrm{h} / \mathrm{s})$

5. Acceleration proportion (\%)

6. Deceleration proportion $(\%)$

7. Idling proportion (\%)

8. Cruising proportion $(\%)$

9. RMS acceleration $\left(\mathrm{m} / \mathrm{s}^{2}\right)$

10. $\operatorname{PKE}\left(\mathrm{m} / \mathrm{s}^{2}\right)$

RMS is given in Eq. 1, and PKE is given in Eq. 2 [5]:

$\mathrm{RMS}=\sqrt[2]{\frac{1}{T}\left(\int_{0}^{T} a^{2} d t\right)}$ 
PKE $=\frac{1}{\operatorname{dist}} \sum_{i=2}^{n}\left\{v_{i}^{2}-v_{i-1}^{2}\right\} \quad\left(\right.$ where $\left.v_{i}>v_{i-1}\right), \quad$ else 0.

Performance value (PV) is typically used to select the candidate cycle that has lowest variation with population parameters [21]. In order to use PV as assessment criteria, target parameters must be calculated for the population as well as for the candidate driving cycles. Percentage deviation is calculated between population parameters and parameters calculated for candidate driving cycles. The summation of absolute values of the deviations, which is $\mathrm{PV}$, is taken after multiplying each absolute deviation by a weightage. In this research, weightage factor was taken as one for all parameters.

A speed acceleration probability distribution (SAPD) graph is commonly used to illustrate driving characteristics and driving pattern smoothness. In general, one graph for population and one graph for candidate cycle must be drawn; a third graph is also required to highlight variation between the other two graphs. However, a simpler method calculates the smallest sum square difference (SSD) between the SAPD graph of the population data set and each candidate cycle, where minimum variation represents the minimum variation of driving pattern with the population data set $[28,29]$. Using this methodology, the representative candidate cycle out of hundreds of driving cycles constructed by software was selected as the driving cycle for the SEW. Graphical representation of the selected driving cycle is shown in Fig. 1, and evaluation of the selected candidate cycle with population parameters is given in Table 4. Primary consideration was given to deviation limits of candidate cycle target parameters with respect to population target parameters. A 5 and $15 \%$ deviation for lower and upper limits, respectively, are typically accepted from population parameters, as in Pune, India driving cycle [30].

\section{Southern Expressway Driving Cycle}

Average speed and average running speed were identical in the SEW driving cycle because the idling proportion of the expressway was zero. The magnitude of acceleration was nearly twice the amount of deceleration (0.452 and $0.247 \mathrm{~m} / \mathrm{s}^{2}$, respectively), but the proportions were similar at 21-23\%. The cruising proportion was high in the SEW driving cycle, representing more than $50 \%$ of total driving. RMS was $1.036 \mathrm{~m} / \mathrm{s}^{2}$ and PKE was $0.138 \mathrm{~m} / \mathrm{s}^{2}$, implying smooth driving conditions compared to other freeways and high mobility roadways worldwide. In addition, the SSD value was smaller, leading to the assumption that the developed driving cycle accurately represents the collected data sample and actual conditions on the SEW.

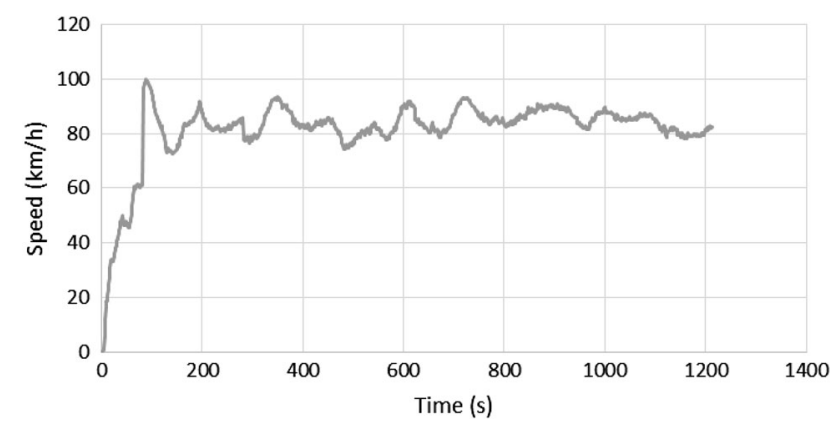

Fig. 1 Driving cycle for Southern Expressway, Sri Lanka

\section{Comparison to Existing Driving Cycles}

A comparison of traffic related parameters in SEW was conducted using 24 well-established driving cycles in France, Germany, the United Kingdom, and Switzerland [2]. A summary of driving cycles is given in Table 5. For the purpose of analysis some parameters were taken into consideration using major statistical categories [21] to compare driving behavior on freeways and high mobility roadways to driving behavior on the SEW. Parameters used to evaluate performance were PKE, RMS acceleration, Average speed, Average running speed, Maximum speed, $\%$ Cruising, \%of acceleration and \%of deceleration. These parameters were selected to create a common platform in order to compare all driving cycles and to identify the traffic conditions at the location of driving cycle constructioned.

Average speed and average running speed imply the overall road condition and length of time for a journey, which should be similar or identical if any given expressway is free of congestion. Maximum speed implies the optimum road condition, and percentage (\%) time for acceleration, deceleration, and cruising implies the driving behavior on the road. Driving behavior is further represented by RMS and PKE values, which indicate how smooth or aggressive the driver is. RMS and PKE values can also imply vehicle-to-vehicle interaction on a road. If the acceleration-deceleration time proportions are high and cruising proportion is low, the assumption can be made that other vehicles or the road itself is creating disturbances.

In comparison to European driving cycles for freeways and high mobility roadways, the SEW driving cycle has lower values for average speed $(80.6 \mathrm{~km} / \mathrm{h})$, with an average running speed $(80.6 \mathrm{~km} / \mathrm{h})$, where most European cycles range from 100 to $130 \mathrm{~km} / \mathrm{h}$. The $\mathrm{SEW}$ demonstrates approximately $25 \%$ time proportions for acceleration-deceleration proportions, while most roads considered in Table 5 have more than $30 \%$. The SEW driving cycle also shows a high cruising time proportion at more than $50 \%$ and lower acceleration and deceleration time 
Table 4 Evaluation of selected candidate cycle with population parameters

\begin{tabular}{|c|c|c|c|}
\hline Parameters for driving cycle evaluation & Population & $\begin{array}{l}\text { Selected } \\
\text { candidate cycle }\end{array}$ & $\begin{array}{l}\text { Percentage } \\
\text { deviation }(\%)\end{array}$ \\
\hline Average speed $(\mathrm{km} / \mathrm{h})$ & 80.420 & 80.645 & -0.28 \\
\hline Average running speed $(\mathrm{km} / \mathrm{h})$ & 80.420 & 80.645 & -0.28 \\
\hline Average acceleration $\left(\mathrm{m} / \mathrm{s}^{2}\right)$ & 0.462 & 0.452 & 2.11 \\
\hline Average deceleration $\left(\mathrm{m} / \mathrm{s}^{2}\right)$ & 0.240 & 0.247 & -3.13 \\
\hline Acceleration proportion $(\%)$ & 24.2 & 21.0 & 13.22 \\
\hline Deceleration proportion $(\%)$ & 22.8 & 23.1 & -1.32 \\
\hline Idling proportion $(\%)$ & 0.0 & 0.0 & 0.00 \\
\hline Cruising proportion $(\%)$ & 53.0 & 55.9 & -5.47 \\
\hline RMS acceleration $\left(\mathrm{m} / \mathrm{s}^{2}\right)$ & 1.153 & 1.036 & 10.16 \\
\hline $\operatorname{PKE}\left(\mathrm{m} / \mathrm{s}^{2}\right)$ & 0.161 & 0.138 & 14.51 \\
\hline Absolute total deviation & & & 50.48 \\
\hline SSD & & & 0.03 \\
\hline
\end{tabular}

Table 5 European driving cycles for freeways [2]

\begin{tabular}{|c|c|c|c|c|c|c|c|c|c|}
\hline No. & Name of the cycle & $\begin{array}{l}\mathrm{PKE} \\
\left(\mathrm{m} / \mathrm{s}^{2}\right)\end{array}$ & $\begin{array}{l}\text { Average } \\
\text { speed }(\mathrm{km} / \mathrm{h})\end{array}$ & $\begin{array}{l}\text { Average running } \\
\text { speed }(\mathrm{km} / \mathrm{h})\end{array}$ & $\begin{array}{l}\text { Max speed } \\
(\mathrm{km} / \mathrm{h})\end{array}$ & $\begin{array}{l}\% \text { of } \\
\text { cruise }\end{array}$ & $\begin{array}{l}\% \text { of } \\
\text { acceleration }\end{array}$ & $\begin{array}{l}\% \text { of } \\
\text { deceleration }\end{array}$ & $\begin{array}{l}\mathrm{Rms} \\
\left(\mathrm{m} / \mathrm{s}^{2}\right)\end{array}$ \\
\hline 1 & Handbook_Sl_incl_pre & 1.784 & 107.3 & 107.33 & 131.2 & 38.4 & 32.97 & 28.63 & 0.038 \\
\hline 2 & Handbook_Cl_incl_pre & 2.006 & 108.2 & 108.72 & 131.1 & 32.4 & 34.13 & 33 & 0.04 \\
\hline 3 & Modem_IM_Motorway & 2.847 & 101 & 102.37 & 128.26 & 23.1 & 39.6 & 36.06 & 0.087 \\
\hline 4 & INRETS aoutoroutes 2 & 2.65 & 94.5 & 94.7 & 131.5 & 28.15 & 41.13 & 30.53 & 0.084 \\
\hline 5 & $\begin{array}{l}\text { LDV_PVU Commercial } \\
\text { cars_motorway_2_total }\end{array}$ & 2.551 & 89.7 & 93.16 & 140.52 & 25.29 & 38.63 & 31.98 & 0.094 \\
\hline 6 & $\begin{array}{l}\text { LDV_PVU light } \\
\text { vans_Empty_motorway_total }\end{array}$ & 3.485 & 81.1 & 81.98 & 117.95 & 17.33 & 42.64 & 38.9 & 0.114 \\
\hline 7 & $\begin{array}{l}\text { LDV_PVU_2.5t } \\
\text { vans_Empty_motorway_total }\end{array}$ & 2.553 & 90.2 & 90.92 & 122.76 & 28.1 & 37.06 & 34.07 & 0.08 \\
\hline 8 & $\begin{array}{l}\text { LDV_PVU_2.8t } \\
\text { vans_loaded_motorway_total }\end{array}$ & 2.108 & 82.7 & 86.01 & 123.42 & 36.06 & 33.22 & 26.88 & 0.093 \\
\hline 9 & $\begin{array}{l}\text { LDV_PVU_3.5t } \\
\text { vans_motorway_total }\end{array}$ & 2.111 & 88.1 & 89.51 & 130.44 & 33.67 & 44.06 & 20.7 & 0.082 \\
\hline 10 & M25 Highspeed Cycle & 2.859 & 101.4 & 102.09 & 146.78 & 22.8 & 40.43 & 36.09 & 0.063 \\
\hline 11 & TRL_WSL motorwat 90 & 0.836 & 93.4 & 93.41 & 98.86 & 56.68 & 20.28 & 23.13 & 0.018 \\
\hline 12 & TRL_WSL motorwat 113 & 0.995 & 112.1 & 112.1 & 118.2 & 50 & 22.27 & 27.73 & 0.02 \\
\hline 13 & $\begin{array}{l}\text { Artemis } \\
\text { mw_150_incl_pre_post }\end{array}$ & 2.955 & 99.6 & 100.35 & 150.37 & 27.81 & 39.7 & 31.74 & 0.092 \\
\hline 14 & $\begin{array}{l}\text { Artemis } \\
\text { mw_130_incl_pre_post }\end{array}$ & 3.014 & 96.9 & 97.6 & 131.43 & 26.03 & 40.64 & 32.58 & 0.093 \\
\hline 15 & $\begin{array}{l}\text { Artemis } \\
\text { LowMot_motorway_total }\end{array}$ & 2.862 & 97.7 & 99.03 & 150.32 & 26.32 & 42.58 & 29.79 & 0.092 \\
\hline 16 & $\begin{array}{l}\text { Artemis } \\
\text { HighMot_motorway_total }\end{array}$ & 2.964 & 102.1 & 103.28 & 156.87 & 24.6 & 41.41 & 32.86 & 0.0082 \\
\hline 17 & EMPA BAB & 1.805 & 117.5 & 117.53 & 160.83 & 35.6 & 38 & 26.4 & 0.027 \\
\hline 18 & EMPA C-2 & 2.088 & 75.3 & 76.11 & 88.37 & 31.88 & 33.7 & 33.33 & 0.052 \\
\hline 19 & EMPA C-3 & 1.566 & 115.3 & 116.17 & 127.14 & 46.08 & 27.95 & 25.26 & 1.566 \\
\hline 20 & EMPA C-6 & 2.423 & 103.4 & 107.63 & 127.2 & 34.9 & 31.06 & 30.1 & 0.09 \\
\hline 21 & EMPA EL1 & 1.794 & 101.7 & 102.29 & 127.2 & 35.1 & 31.43 & 32.9 & 0.039 \\
\hline 22 & EMPA T100 & 1.256 & 100 & 100.03 & 107.32 & 41.1 & 31.33 & 27.57 & 0.023 \\
\hline 23 & EMPA T115 & 1.022 & 115 & 115.01 & 122.44 & 49.37 & 26.07 & 24.56 & 0.019 \\
\hline 24 & EMPA T130 & 0.999 & 130 & 130 & 137.72 & 54.14 & 26.07 & 19.8 & 0.016 \\
\hline
\end{tabular}


proportions compared to other driving cycles for freeways and high mobility roadways. The SEW driving cycle also demonstrates the lowest PKE value of $0.138 \mathrm{~m} / \mathrm{s}^{2}$ but a high RMS value of $1.036 \mathrm{~m} / \mathrm{s}^{2}$.

\section{Conclusion}

A results comparison of the SEW driving cycle and freeways and high mobility roadways showed that the average and running speeds for the SEW were below the median speed of the other cycles. However, speed limits and mean speeds vary by country, and road geometry (e.g., lane width, shoulder width, and surface condition), weather conditions, and traffic volumes can be contributory factors to determine average and running speeds. Furthermore, a $20 \%$ drop in average speed was observed for the SEW as compared to its maximum running speed because most drivers were inexperienced expressway drivers since the SEW is the first expressway in Sri Lanka. In addition, because the SEW is surrounded by beautiful scenery and SEW drivers are not commuters, drivers typically intentionally drive slowly.

The time proportion for cruise (55.9\%) was well above the half of the time spent on the expressway; most of the other driving cycles had lesser cruising proportions than the SEW. Acceleration and deceleration proportions were approximately $25 \%$, which is relatively lower than driving cycles considered in Sect. 4 and summarized in Table 5. PKE was lowest among considered driving cycles, but RMS value was bit higher, leading to the conclusion that the driving behavior is smooth on the SEW. Results also showed that fuel performance will be better due to lower PKE than PKE values in driving cycles in other countries.

Previous research has identified that fuel performance improves when vehicle speed is in the range of $50-80 \mathrm{~km} /$ $h$ [31]. Because the average speed on the SEW was approximately within the $50-80 \mathrm{~km} / \mathrm{h}$ range, it can be believed that the emission inventories are lower than other highways assuming that vehicle conditions and fuel conditions (clean fuel) are identical in all countries. This conclusion was also supported by lower PKE values for the SEW. Future research should focus on vehicle condition and fuel condition parameters and accurately measure fuel consumption and emission inventories using the model and performing a chassis dynamometer test with a gas analyzer.

Acknowledgments Authors are thankful to Dr. Thusitha Sugathapala for the guidance and motivation given and further thank goes to Sustainable Energy Authority for the resources provided for the success of this research.

\section{References}

1. Tong H, Hung W (2010) A framework for developing driving cycles with on-road driving data. Transp Rev 30(5):589-615. doi:10.1080/01441640903286134

2. Barlow TJ, Latham S, McCrae I, Boulter P (2009) A reference book of driving cycles for use in the measurement of road vehicle emissions, TRL Limited

3. Nesamani K, Subramanian K (2011) Development of a driving cycle for intra-city buses in Chennai, India. Atmos Environ 45(31):5469-5476. doi:10.1016/j.atmosenv.2011.06.067

4. Han DS, Choi NW, Cho SL, Yang JS, Kim KS, Yoo WS, Jeon CH (2012) Characterization of driving patterns and development of a driving cycle in a military area. Transp Res Part D Transp Environ 17(7):519-524. doi:10.1016/j.trd.2012.06.004

5. Tong H, Hung W, Cheung C (1999) Development of a driving cycle for Hong Kong. Atmos Environ 33(15):2323-2335. doi:10. 1016/S1352-2310(99)00074-6

6. André M (2004) The ARTEMIS European driving cycles for measuring car pollutant emissions. Sci Total Environ 334-335:73-84. doi:10.1016/j.scitotenv.2004.04.070

7. Andre M (2004) Real-world driving cycles for measuring cars pollutant emissions-part a: the Artemis European driving cycles. Rep Inrets LTE 411:97

8. Nutramon T, Supachart C (2009) Influence of driving cycles on exhaust emissions and fuel consumption of gasoline passenger car in Bangkok. J Environ Sci 21(5):604-611. doi:10.1016/ S1001-0742(08)62314-1

9. André M, Rapone M (2009) Analysis and modelling of the pollutant emissions from European cars regarding the driving characteristics and test cycles. Atmos Environ 43(5):986-995. doi:10. 1016/j.atmosenv.2008.03.013

10. Hung W, Tong H, Cheung C (2005) A modal approach to vehicular emissions and fuel consumption model development. J Air Waste Manag Assoc 55(10):1431-1440. doi:10.1080/ 10473289.2005.10464747

11. Kumar R, Durai BK, Saleh W, Boswell C (2011) Comparison and evaluation of emissions for different driving cycles of motorcycles: a note. Transp Res Part D Transp Environ 16(1):61-64. doi:10.1016/j.trd.2010.08.006

12. Gamalath I, Galgamuwa U, Fernando C, Perera L, Bandara JMSJ (2012) Methodology to develop a driving cycle for a given mode and traffic corridor; case study for Galle Road, Colombo, Sri Lanka. In:Proceedings of the Civil Engineering Research for Industry Symposium, Moratuwa, pp 45-50

13. Road Development Authority, Sri Lanka. 3/28/2014. http://www. rda.gov.lk/supported/expressways/stdp.htm. Accessed 30 Oct 2015

14. Hung W, Tong H, Lee C, Ha K, Pao L (2007) Development of a practical driving cycle construction methodology: a case study in Hong Kong. Transp Res Part D Transp Environ 12(2):115-128. doi:10.1016/j.trd.2007.01.002

15. Barrios C, Domínguez-Sáez A, Rubio J, Pujadas M (2012) Factors influencing the number distribution and size of the particles emitted from a modern diesel vehicle in real urban traffic. Atmos Environ 2012;5616-25. doi:10.1016/j.atmosenv.2012.03.078

16. Tong H, Tung H, Hung W, Nguyen H (2011) Development of driving cycles for motorcycles and light-duty vehicles in Vietnam. Atmos Environ 45(29):5191-5199. doi:10.1016/j.atmosenv. 2011.06.023

17. Tamsanya S, Chungpaibulpattana S, Atthajariyakul S (2006) Development of automobile Bangkok driving cycle for emissions and fuel consumption assessment. In: Proceedings of the 2nd joint international conference on sustainable energy and environment (SEE 2006) 
18. Kent J, Allen G, Rule G (1978) A driving cycle for Sydney. Transp Res 12(3):147-152. doi:10.1016/0041-1647(78)90117-X

19. Tong H, Hung W, Cheung C (2000) On-road motor vehicle emissions and fuel consumption in urban driving conditions. J Air Waste Manag Assoc 50(4):543-554. doi:10.1080/10473289. 2000.10464041

20. André M, Joumard R, Vidon R, Tassel P, Perret P (2006) Realworld European driving cycles, for measuring pollutant emissions from high- and low-powered cars. Atmos Environ 40(31):5944-5953. doi:10.1016/j.atmosenv.2005.12.057

21. Galgamuwa U, Perera L, Bandara S (2015) Developing a general methodology for driving cycle construction: comparison of various established driving cycles in the world to propose a general approach. J Transp Technol 5(04):191. doi:10.4236/jtts.2015.54018

22. Dai Z, Niemeier D, Eisinger D (2008) Driving cycles: a new cycle-building method that better represents real-world emissions. Department of Civil and Environmental Engineering, University of California, Davis

23. Khan M, Abdel-Rahim A, Williams CJ (2015) Potential crash reduction benefits of shoulder rumble strips in two-lane rural highways. Accid Anal Prev 2015;7535-42. doi:10.1016/j.aap. 2014.11.007

24. Zito R, Primerano F (2005) Drive cycle development methodology and results. Transport System Center, University of South Australia, Australia
25. Berry DS, Belmont DM (1952) Distribution of vehicle speeds and travel times. In: Proceedings of the second Berkeley symposium on mathematical statistics and probability, the regents of the University of California, pp 589-602

26. Hashim IH (2011) Analysis of speed characteristics for rural twolane roads: a field study from Minoufiya Governorate, Egypt. Ain Shams Eng J 2(1):43-52. doi:10.1016/j.asej.2011.05.005

27. Hustim MR, Isran M (2013) The vehicle speed distribution on heterogeneous traffic: space mean speed analysis of light vehicles and motorcycles in Makassar-Indonesia. In: Proceedings of the Eastern Asia Society for Transportation Studies, vol. 9

28. Lyons T, Pitts R, Blockley J, Kenworthy J, Newman P (1990) Motor vehicle emission inventory for the Perth Airshed. J R Soc West Aust 72(3):67-74

29. Lin J, Niemeier DA (2002) An exploratory analysis comparing a stochastic driving cycle to California's regulatory cycle. Atmos Environ 36(38):5759-5770. doi:10.1016/S1352-2310(02)00695-7

30. Kamble SH, Mathew TV, Sharma G (2009) Development of realworld driving cycle: case study of Pune, India. Transp Res Part D Transp Environ 14(2):132-140. doi:10.1016/j.trd.2008.11.008

31. Olsvik I (2011) Measures to reduce GHG emissions and improve air quality. Nord Road Transp Res 2:11 